furnace to the hammer, and for moving them when under the hammer. 3. Improved hammers, with a clear unfettered fall, and with sich width of standards as to give the workmen all the comfort and convenience possible in executing the necessary operations of shaping, forging, and cutting the material to the required form.

On Hammering and StonenDressing Machinery.-Dr. J. H. Ll yyd. The author claimed to have devised machinery which was particularly applicable for cutting, sawing, chiselling, drilling, and dressing stome and other substances, for forging and hammering metals, and for working the tools in general by motive power, so as to supersede hand-labour. The invention has not yet been applied ; incleed, the improved machinery as yet only exists in the state of a model. The paper was illustrated by numerous drawings.

\section{REPORT'S OF COMMITTEES}

\section{REPORT OF THE RAINFALL COMMITTEF}

This report was read by Mr. G. J. Symons, the secretary of the committee. It commenced by referring to the steps taken last year to secure uniformity in the registration of rain by the observers throughout the country, and to the acceptance by the General Committee of the recommendation of the Rainfall Committee that additional observers should be obtained in parts of the country where at present such observers are far from one another. Dartmoor was last year quoted as an illustration; thither after last meeting Mr. Symons proceeded, and the result is that the number of stations in that district has been doubled. There are, however, still two parts of the moor where no one lives, and no one has yet been found willing to superintend a gauge. Reference is next made to other steps taken by the committee to secure returns from various other districts, and to the success of these efforts. The committee close this portion of their report by pointing out that to keep up an amateur staff adequate to the requirements of the subject, say from 1,500 to 2,000 observers, it is indispensable that a number of new ones be enlisted each year to supply vacancies caused by deaths and removals, and they therefore intimate their desire to receive through their secretary (Mr. G. J. Symons, 62, Camden Square, London) offers of assistance from parties willing to provide themselves with the inexpensive and simple gauge now generally in use. The report then proceeded to mention that the secretary has during the past year visited and examined the gauges in use at upwards of one hundred stations. By this personal intercourse greatly improved accuracy and uniformity of procerlure is secured. The committee regret that through want of funds they have been unable to make any progress with the collection of old returas during the past year. The report then proceeds to describe certain experiments cartied ont at Calne, in Wiltshire, by Colonel $\mathrm{W}^{\prime}$ ard, with a view to determining the difference in the amount of rain collected at various heights above the ground, not so much with a view to determining the cause of this variation as its amount, and therefrom the possibility or otherwise of reducing observations made with gauges at different heights above the ground to what they would have been at some uniform datum. This portion of the report commences by a brief notice of the experiments made by Prof. Phillips at York in the years 1832-35, then pass on to illustrate the necessity for the determination of these corrections; thence to a description of the instruments employed, and their position; and then follow a heavy batch of tables of the calculations and the results which it is impossible to abbreviate: Part of the conclusions were exhibited in the form of diagrams representing the total rainfall on the surface of the ground, and its decrease at various altitudes above it, one diagram giving the mean annual decrease, and a series of twelve others the monthly curves; from these it was perfectly obvious that the difference between a gauge on the ground and one 20 ft. high is in winter nearly three times as great as in summer, and hence it becomes evident that the mean annual correction is applicable to the total fall in one or more years only, and not to individual months, for each of which separate corrections are given. The report then proceeds to consider the most suitable height for the orifice of gauges to be above ground, and gives various reasons pro and con, finally concluding that Ift., as hitherto adopted, be still recommended. The report next refers to the tables in an appendix giving the monthly fall of rain at about 300 stations during the years $1868-69$, and to varions calculations in different states of progress: The report concludes by pointing out the great work being done by the yoluntary and entirely gratuitous services of nearly 2,c00 observers, and suggests that it would be alike graceful and an economical act on the part of the Government were they to offer to relieve the observers from the cost of reducing and publishing the observations which are now by their accuracy and completeness accepted as a type by foreign countries and our own colonies, and which are found yearly more and more useful in relation to our manufacturing and commercial interests. The committee conclude with the following words :"A few hundreds annually would probably suffice to hold together a body of practised observers which has no equal in the world, and which once broken up, could not be replaced, since, irrespective of the difficulty of training the new observers, the continuity of the observations would be destroyed."

\section{SCIENTIFIC SERIALS}

The Geological Magazine for September (No. 75) opens with an important article by Mr. E. Ray Lankester, describing a new species of Cephalaspis ( $C$. dawusoni) from the Devonian sandstones of Gaspé, in Canada. This fish is figured, as also a spim, Machairacanthus sulcatus, which was found associated with it. Mr. Lankester also describes the characters of Scaphaspis knerit. - Mr. Davidson continues his descriptions of Italian tertiary Brachiopoda, which he illustrates with two fine plates containing a great number of figures.-Mr. Alfred Marston contribites a paper on the transition beds between the Silurian and Devonian rocks ; and $\mathrm{Mr}$. Lankester describes and figures a supposed new species of Terebratula ( $T$. rex), obtained from East Anglian drifts, but probably derived from beds of Portlandian age. The remaining articles in the number are a catalogue of mammalian fossils which have been discovered in Ireland, by Mr. R. H. Scott, and a reply by Archdeacon Pratt to some remarks by M. Delaunay on Mr. Hopkins's method of determining the thickness of the earth's crust.

THE Fournal of Botany for October commences with some Observations on Willows, by the Rev. J. E. Leefe. Dr. Hance contributes some carpological notes on Chinese plants; and Mr. A. W. Bennett his paper on the relative period of maturity of the male and female organs in hermaphrodite plants, read at the Liverpool meeting of the British Association, of which an abstract has already appeared in our columus. Dr. Ferdinand von Müller has a note on some interesting plants gathered near Lake Barlee during Mr. Forrest's recent expedition; and among the borrowed abstracts is one of Mx. Bailey's useful paper on the natural ropes used for packing cotton bales in the Brazils, read before the Literary and Philosophical Society of Manchester.

THE two longest articles in the American Naturalist for September are a reprint of Mr. Darwin's memoir on the movements and habits of Climbing Plants, and a highly favourable review of Wallace's "Contributions to the Theory of Natural Selection." Prof. Cope contributes an article on the Fauna of the Southern Alleghanies, and Dr. C. C. Abbott one on Mudliving Fishes. One of the most interesting papers in the num. ber is a very short one by Dr. William Stimpson on the Deepwater Fauna of Lake Michigan, containing a short account of a series of dredging operations which has been undertaken in this lake during the present year by the Chicago Academy of Sciences. At a distance of eighteen miles from Chicago, where the depth was fourteen fathoms, the sandy or gravelly bottom was found to be nearly barren of life. Between the distances of twelve and twenty-two miles from off Racine, the average depth was forty. five fathoms, and the bottom generally a reddish or brownish sandy mud. This bottom was found to be rather densely in habited; the captures including a Mysis allied to Arctic forms, which led the author to refer its original entry into the lake to the cold period of the quaternary epoch, two species of Gammarus, a small white Planaria, and a new species of Pisidium. The investigation of the materials obtained by the dredging parties of the Academy is now in progress, and the results will be published in full with iilustrations at an early period.

\section{SOCIETIES AND ACADEMIES} BRISTOL

The Observing Astronomical Society.--Report of Observations made during the period from Ang. 7 to Sept. 6, 1870 , inclusive. - Solar Phenomena:-Mr. T. G. E. Elger, of Bed- 